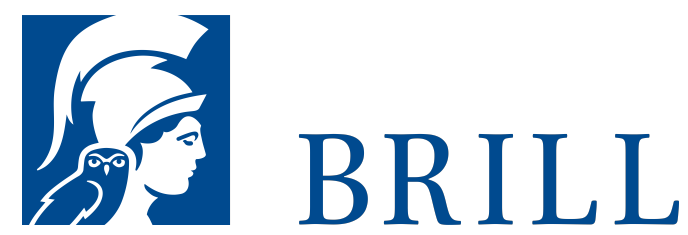

\title{
Weltgestaltung durch Sprache
}

Phänomenologie der sprachlichen Kreativität und der interkulturellen Kommunikation

Author: Andris Breitling

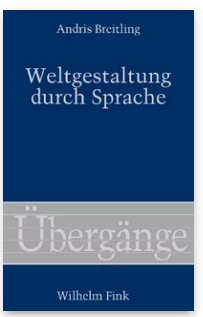

Die Sprache bildet die Welt nicht einfach ab, sondern gibt dem, was uns in der Erfahrung begegnet und was wir denkend erfassen, jeweils einen bestimmten Sinn und damit eine bestimmte Gestalt.

Ausgehend von dem methodischen Ansatz einer Phänomenologie der Sprache, wie sie vor allem von Maurice Merleau-Ponty entwickelt worden ist, wird untersucht, wie verschiedene Formen sprachlicher Sinnbildung einen neuen Blick auf die Welt, eine neue »Weltansicht « im Sinne Wilhelm von Humboldts eröffnen können. In Analysen zur Grammatik, zur Begriffsbildung und zum kreativen Sprachgebrauch werden Spielraum und Grenzen sprachlicher Weltgestaltung ausgelotet. Am Modell der Übersetzung wird schließlich gezeigt, wie trotz der Vielfalt sprachlicher Weltansichten eine Verständigung zwischen Angehörigen verschiedener Sprach- und Kulturgemeinschaften gelingen kann.

Pages: 362

Seiten

Language:

German

Subjects: 19th \& 2oth Century

Philosophy, Philosophy

Publisher: Brill | Fink

Series:

Übergänge,

Volume: 70

E-Book (PDF)

Released online: O4 Sep 2017

ISBN: $978-3^{-}$

8467-6o31-4

List price

Hardback

Publication date: 14Jul 2017

ISBN: 978-37705-6o31-8

List price 
Andris Breitling studierte Philosophie in Canterbury und Warwick. Er war Mitglied des Graduiertenkollegs „Phänomenologie und Hermeneutik“ an der Ruhr-Universität Bochum und Wissenschaftlicher Mitarbeiter am FrankreichZentrum der Technischen Universität Berlin. Nach seiner Promotion war er Wissenschaftlicher Mitarbeiter am Institut für Philosophie der Universität Rostock, danach habilitierte er sich. Seitdem ist er Professor für Ethik, Sozialphilosophie und Kulturtheorie am Fachbereich Sozialwesen der Hochschule Niederrhein.

For more information see brill.com

Order information: Order online at brill.com +443303330049 | customerservices@brill.com Submission information: brill.com/authors

Titles published by Brill | Fink, Brill | mentis or Brill | Schöningh: +49(o)71 5413279216 | brill@brocom.de 